\title{
The present Situation and Enlightenment of Chinese Teacher Training in Malaysia
}

\author{
Kehua $\mathrm{Yu}$ \\ Overseas Education College of Xiamen University \\ China \\ yukehua@163.com
}

\begin{abstract}
Malaysia retains a complete system of Chinese education and Chinese teachers' role as the machine tool of Malaysian Chinese education. This paper is designed to provide reference for the training of international Chinese teachers by analyzing the unique advantages of Chinese teachers' development in Malaysia, and teasing out the present situation, characteristics and existing problems of Chinese teachers training.
\end{abstract}

Keywords-Malaysia, Chinese teachers, teacher training, enlightenment

\section{INTRODUCTION}

With a history of nearly 200 years, Malaysia's Chinese education has retained a complete system of Chinese education from pre-school, elementary, secondary to higher education. At present, Chinese courses are given not only in Chinese schools, but in the major national system including elementary, secondary to higher education. As the "Chinese fever" has been on rise, the number of Chinese teachers in Malaysia is far from enough so that more than 90,000 are demanded[1]. The development of the "One belt and One road" initiative has taken the cooperation between Malaysia and China to a higher level in politics, economy, culture, education and other areas, and has further stimulated Malaysia's demand for Chinese teachers and international Chinese talents. Chinese teachers' development in Malaysia has its own unique advantages as they not only meet the need of the domestic market, but serve other Southeast Asian countries. Most of previous studies of Chinese teachers in Malaysia are devoted to the existing problems facing them [2]-[4], instead of the current situation and problems of their training, not taking into account the unique advantages of its development. Accurate understanding of the current situation of the Chinese teacher training is of great practical significance to the construction of the Malaysian Chinese teachers' team and the development of Chinese teachers in other countries, and it also works as an important basis for the training program and goal of international Chinese talents. Therefore, the study of Malaysian Chinese teacher training merits further discussion.

This paper is to discuss: (1) What are the unique advantages of Chinese teacher development in Malaysia? (2) What about the present situation of Chinese teacher training in Malaysia? (3) What are the implications of Chinese teachers training in Malaysia for other countries?

\section{ThE UnIQUE ADVANTAGES OF CHINESE TEACHER DEVELOPMENT IN MALAYSIA}

Thanks to globalization and China' role as the world's second largest economy, the "Chinese fever" continues to rise worldwide. Since the 1990s, the Malaysian government has been increasingly open to Chinese education as it began to change its long-term single language education policy of "One country, one language, and one source of origin". Malaysian government officials and non-Chinese people have all followed the trend of learning Chinese and Malaysians are more intended to learn Chinese as the second language. In order to meet the needs of the sustainable development of domestic Chinese education, the Malaysian government, United Chinese School Committee's Association of Malaysia (UCSCAM), United Chinese School Teachers' Association of Malaysia (UCSCTAM), private secondary schools, private Chinese institutions of higher learning, Confucius Institute Headquarters (Hanban) and Overseas Community Affairs Council, Republic of China (Taiwan) set up efforts to support Chinese teachers training in various forms, through various channels and with various methods. As a result, the Chinese teachers have been on the rise at a fast rate, which effectively helps resolve the trouble of "the shortage of teachers" to a certain extent. Compared with Chinese teachers' education in Southeast Asia or even the rest of the world, Chinese teacher development in Malaysia has its unique advantages manifested by the following essentials.

\section{A. Advantages of Chinese education}

Malaysia retains the world's most complete education system of Chinese as its mother language with its unique Chinese education in the world. Chinese has been serving as the mother tongue, the first language and teaching language in Chinese elementary schools, private secondary schools and private institutions of higher learning at all times. Chinese education in Malaysia has five advantages: complete education system, standardized curriculum system and management mechanism, abundant Chinese students, solid people's foundation and strong organizational safeguards [5]. Therefore, Malaysia's overall Chinese levels are better than those of any other country, and have higher-quality of Chinese teachers, providing important sources of Chinese teachers to any other Southeast Asian countries, such as Singapore, Indonesia and Brunei. 


\section{B. Geographical advantages}

Located in the center of the two continents and the two oceans, Malaysia roles as key links between Asia and Oceania north-south and between the Pacific and the Indian Ocean eastwest. As a critical waterway connecting the two oceans in a very favorable geographic position, the Malacca Strait boasts one of the world's busiest straits open to navigation with the largest shipping amount for the longest duration. Besides, collectively known as "Nanyang", Malaysia and other Southeast Asian countries share similar histories, cultures, natural climate and living habits so that Chinese people residing in different Southeast Asian countries share similar fate. Chinese people are closely associated in those neighboring regions and cities such as southern Malaysia and Singapore, northern Malaysia and Thailand, Penang and Medan, Kuching and Singkawang, and Miri and Brunei[6]. Therefore, Malaysian Chinese teachers training can serve both it and the neighboring countries with geographical advantages to become the center for Chinese teacher training in Southeast Asia.

\section{Advantages of cultural integration}

Although Hanban designates a large number of volunteers to teacher Chinese in Malaysia every year, the "quantity" and "quality" of Chinese teachers remain to be improved essentially despite the alleviation of "shortage of teachers". The main cause is the difficult adapting and assimilating themselves to the indigenous culture of Malaysia. Moreover, just as the proverb "Distant water can't quench present thirst" puts it, the use of foreign-aid teachers is only a matter of expediency for Malaysian Chinese education. Instead, the cultivation of native Chinese teachers has been a consensus of worldwide experts and scholars. Due to its marked geographical advantages and similar national conditions, language, culture, diet and climate to those of other Southeast Asian countries, native Chinese teachers in Malaysia will have strong cultural adaptability to Chinese teaching environments of those countries quickly, and be more likely to satisfy the needs of Southeast Asian countries for Chinese teachers.

\section{Advantages of progressively easing policy on Chinese teacher education}

Since the 1990s, the Malaysian government started to relax its regulation on and support the development of Chinese education in order to accelerate the globalization process, which has improved Chinese teachers' status, pay and education. With Chinese teaching included in the national education system, Malaysia's public elementary schools, secondary schools and institutions of higher learning have all offered compulsory or selective courses Chinese courses. Due to increasing diversity of Chinese learners, the Malaysian government has placed progressive emphasis on the shortage of Chinese teachers. The Ministry of Education has taken measures to promote the development of Chinese teachers. For instance, as the institution of teacher education management, the Teachers' Committee of the Ministry of Education is responsible for on-the-job training and pre-job training for teachers. At present, 31 teacher training institutes in Malaysia offer training and diploma program to whoever doesn't graduate from universities in order to meet the needs for primary and secondary school teachers. Chinese teachers training courses are opened in 15 of those institutes in which Chinese teachers are required to take teaching theory courses in 5 semesters and teaching practice $\&$ training in one semester. Then one obtains the teacher's certification issued by the Malaysian Ministry of Education before passing the required examinations. The learner is not only exempt from tuition and lodging fees, but also given subsistence allowance. To solve the shortage of elementary Chinese teachers, the Ministry of Education has re-opened holiday teacher training classes to train more provisional teachers to be qualified ones, recruit more Chinese training teachers, and reduce the requirements for teachers to be trained, and continue to rehire the retired as contract teachers. At the same time, the Ministry also offers Chinese teacher training courses for graduates to train elementary and secondary Chinese teachers and has approved the establishment of private Chinese universities \& colleges to develop reserve Chinese teachers.

\section{E. Advantages of Chinese community}

The prosperity of Chinese education in Malaysia is in large part attributed to the efforts of Chinese community leaders UCSCAM and UCSCTAM and the Malaysian government's continuous fight to firmly defend Chinese education development. In view of the fact that Malaysian government and the Ministry introduced the policy of restricting Chinese education and of the shortage of Chinese teachers, UCSCTAM not only provides prompt enrolment information of Chinese teacher training for those who intend to sit the exams for admissions to Chinese teaching, but also assists those candidates who qualify for but lose the exams in lodging complaints to the Ministry, fighting for their qualification of registering for the exams and admissions. In order to promote the professional development of private secondary school teachers, the Student Affairs Division and the Teacher Institute of UCSCAM not only set up a "Special scholarship for teachers education in private secondary schools" and "Lin Huangsheng education fund loans", but established a "seed teacher" talent pool to train private secondary school teachers. Moreover, the Teacher Institute, UCSCAM compiled "The Handbook of Teacher Training Programme and Further Education Scholarship" and set up a "Special scholarship for Chinese teacher training of private secondary schools" in order to broaden the channels for private secondary students' further education and employment. Meanwhile, UCSCAM works with mainland China and Taiwan teacher training educational institutions to jointly develop teachers for private secondary schools. In addition, the council is committed to promoting the reorganization of private secondary students' education diplomas by the Malaysian government, and offer training courses and workshops for Chinese teachers of private secondary schools to improve their teaching levels. The two councils also formulated "The Reference Guide for Chinese Teachers' Salary and Welfare in Private Secondary Schools" to improve their salary \& welfare and set up "Shen Muyu Teacher Award" and other awards to ensure that Chinese teachers work effectively. 


\section{Present Situation of Chinese Teacher Training In MALAYSIA}

"Shortage of Chinese teachers" remains a salient problem to be resolved in Malaysian Chinese education for nearly 40 years. Chinese education leaders of UCSCAM and UCSCTAM have been engaged in continuous conflict and cooperation with the Ministry of Education on "quantity" and "quality" of Chinese teachers, which has prompted the Malaysian government to gradually take some mitigation measures. Chinese teacher training in the national education system has been progressively put on the Malaysian government's agenda while the training in the private Chinese education system mainly depends on school-based research and assistance of UCSCAM, UCSCTAM, Chinese institutions of higher learning, Taiwan and mainland universities.

\section{A. Holiday Training Classes for Provisional Teachers Run by the Ministry of Education}

Provisional teachers are an important source of elementary Chinese teachers and there are thousands of them in Malaysia. To improve quality of elementary Chinese teachers, the Ministry urges on-the-job provisional teachers to obtain teacher certification by Implementing: (1) on-the-job training program for provisional teachers with college diplomas (KPL1-LPBS) and holiday teacher training classes (DPLI-SR KDC). Those teachers can be promoted as qualified teachers through 1.5year training; (2) holiday training classes for provisional teachers without college diplomas (DPLIKDC). Those teachers can be promoted as qualified teachers through 18-month holiday teacher training classes in the normal college; (3) university qualification courses for non-university teachers (PKPG). The courses were opened during 2001-2006 to help non-university teachers acquire university qualifications.

In addition, the Ministry builds up the team of elementary Chinese teachers by recruiting more Chinese teacher trainees, reducing the requirements for teachers to be trained, and continuing to rehire the retired as contract teachers. Since 2011, the government has gradually lowered the bar for the enrolment of Chinese teacher trainees including graduates from private secondary schools in addition to those from public (Chinese) secondary schools and with SPM.

Private secondary school teachers are mainly trained by the Student Affairs Division and the Teacher Team of the Teacher Institute UCSCAM, Office of Academic Affairs or Office of Teacher Training of the schools, Malaysia's higher vocational schools, The Federation of Alumni Associations of Taiwan Universities Malaysia and The Association of Graduates from Universities and Colleges of China Malaysia [7]. In fact, UCSCTAM and universities \& colleges of mainland China and Taiwan are also dedicated to Chinese teachers training of private secondary schools. The main trainers are as follows.

\section{B. The Student Affairs Division and the Teacher Team of the Teacher Institute UCSCAM}

The Teacher Team of UCSCAM is responsible for private secondary school teacher education, including the development of teacher training resources and the organization of on-the-job teacher training courses. Specifically, tasks are listed as follows: organizing on-the-job teacher training courses, training new teachers from private secondary Chinese schools, promoting teacher training programs, retaining excellent teachers of those schools, seeking welfare for teachers of the schools, stable construction of professional teachers teams, construction and improvement of teachers' education network, continuing the urge of teachers to read "Diploma Program for Education", and collection and compilation of Reference for the Teacher Evaluation System of Private secondary Chinese Schools. In 2017, teacher training activities organized by The Teacher Team include training of new teachers, teacher training classes in different subjects, guided technical training, educational seminars, Chinese teaching demonstration \& communication meetings, overseas cultural teaching guidance, class-teacher workshops, principals and administrative staff workshops, Education Management and Administration Master program, new material description, etc. It can be seen that the teacher training courses offered by the Institute cover different categories: teaching training, research training, test training, administrative training and textbook training. The wide coverage of training targets includes new teachers, teachers in various subjects, class teachers, administrative staff and leaders. The training is implemented in the headquarters of private secondary schools and in even mainland China and Taiwan apart from in UCSCAM. Therefore, the on-the-job training of private secondary school teachers offered by the Institute roles as an important path to the teachers' professional growth. In addition, UCSCAM introduced the teaching model of "success education" from The Eighth Secondary School Zhabei Shanghai in 2009, organized a training program of "success education" for teachers, and followed the real-time training in schools and engaged in classroom observation and communication.

\section{United Chinese School Teachers' Association of Malaysia (UCSCTAM)}

United Chinese School Teachers' Association of Malaysia (referred to as UCSCTAM for short) is a teacher organization composed of the federation of Chinese school teachers' unions in all regions and states. Amid at making friendly contacts among Chinese school teachers and seeking welfare for them, the association has long been committed to improving professionalism of those teachers and offered various on-thejob training courses, lectures and workshops for pre-school and elementary Chinese school teachers, including "Care and growth series courses_to honor the teacher and respect his teaching", "Teachers' pressure decoding workshop", "Regulate the internal and return to nature" (body, mind and soul healing workshop), "Meeting with yourself" (Teachers' mind growth workshop), 2010 research-teaching-education workshop in Kuala Lumpur and Selangor Chinese schools, "Chinese reading skills-elementary Chinese teaching method" training courses, correct Mandarin pronunciation training courses for Malaysian Chinese school teachers, 2010 Chinese teaching skills training courses for Malaysian elementary Chinese school teachers, Chinese demonstration teaching class of elementary Chinese schools, overseas studies teams of Chinese schools teachers. UCSCTAM not only attaches importance to the improvement of Chinese school teachers' teaching skills, but pays close attention to their mental health and emotional management. 


\section{The Education Department in the New Era University}

In order to meet the individual needs of Malaysia Chinese Independent Secondary School, the Education Department of the New Era University also plans and arranges the school training courses. According to the work report of the school (academic department) in 2015, the education department had been set up 17 teaching workshops for the teachers of the Malaysia Chinese Independent Secondary School during the year, as shown in table 1. The training courses involve education, teaching skills, class management, teachers' emotions, and communication between teachers and students, etc..

TABLE I. SCHOOL-BASED TraINING COURSES SET By NEW ERA UNIVERSITY IN 2015

\begin{tabular}{|c|l|}
\hline & Training for Novice teacher \\
& Can only be true?--Find original intention of being a \\
& teacher \\
& Teaching workshop of mathematical exploration \\
& Guidance \\
& How to communicate with children effectively \\
& Class management \\
Subject of School-based & Workshop on creative teaching practice \\
Training Courses & The combination of theme integration teaching and \\
& application of picture books \\
& Work ethic \\
& Ethics and gratitude culture \\
& Know yourself first, then teach others (Chinese and \\
& English versions) \\
& Teaching principle and practice and class management \\
& (Malay version) \\
\hline
\end{tabular}

\section{E. Confucius Institute}

Recently, there are two Confucius Institutes built in Malaysia. For one, it is the Confucius Institute of the University of Malaya, which is jointly built by Beijing Foreign Studies University and Malaya University, for the other, it is the Confucius Institute of Century University, which is jointly established by Hainan Normal University and Century University. The Confucius Institute of the University of Malaya trains the local Chinese teachers by organizing special reports on Chinese teaching, holding seminars on Chinese language teaching regularly, and giving open classes and so on. The special reports about "how to do with Chinese characters and reading teaching during the Chinese teaching" and "Chinese culture in the reflection of traditional Chinese festivals" was set up by the teachers of the Confucius Institute of the University of Malaya, which attracted the participation of 335 local Chinese teachers from Malaysia primary school, and was warmly welcomed by local Chinese teachers.

\section{F. Taiwan Overseas Chinese Affairs Commission and Council on Chinese Overseas Educational Exchange}

The overseas Chinese management institutions from Taiwan and mainland have established close cooperative relations with the Malaysian directors and Chinese schools, which is to train the working Chinese teachers in Malaysia. In order to improve the teaching level of Chinese teachers in Malaysia, Taiwan Overseas Chinese Affairs Commission has organized teachers to use the winter and summer holidays to train in Taiwan. The training courses are counseling sessions, teaching courses, educational and cultural visits. First, the counseling sessions are mainly targeted at education of special education groups and child behavior counseling. Second, the teaching courses mainly improve the teaching skills, including creative teaching and active teaching. And last but not least, the educational and cultural visits help Chinese teachers from Malaysia understand the situation of education in Taiwan and the local people. In order to improve the teaching ability of the teachers in Chinese primary school in Malaysia and let them know the education situation of Chinese schools, Council on Chinese Overseas Educational Exchange organizes courses on teaching skills and Chinese cultures in Chinese universities, and it also has teaching and cultural visits in the mainland of China. The council also devotes itself to training the administrators of the Chinese schools in Malaysia, organizing them to go to China and giving a platform for them to interact some problems with China's experienced school leaders, such as the training and management of Chinese teachers, the construction of school-based curriculum and the construction of school culture. What is more, since 2016, the Council on Chinese Overseas Educational Exchange and the Office of Overseas Chinese Affairs under the PRC State Council associated with Chinese language department of Jinan University, carrying out the qualification training of Malaysian Chinese teachers, to improve the professional level of Chinese teachers. The content of the training mainly includes Chinese phonetic alphabet, Chinese grammar teaching, Chinese knowledge and ability, Chinese culture and history, Chinese writing training and the training of words, word groups, reading and speaking in Mandarin.

\section{The Characteristics ANd Problems of Chinese TEACHER TRAINING IN MALAYSIA}

\section{A. The Characteristics of Chinese Teacher Training in Malaysia}

\section{1) Diversity of Training Subjects}

The training subjects of Chinese teachers in Malaysia involve educational institutes and Chinese communities, such as the Ministry of Education, UCSCAM, the Faculty of Education and the Education Department of the New Era University, and China's Confucius Institutes, Council on Chinese Overseas Educational Exchange and Taiwan Overseas Chinese Affairs Commission are also included. The combination of foreign and domestic administrative department, 
cultural and educational organization and other parties jointly promotes the development of Malaysian Chinese teachers.

\section{2) Diversified Categories of Training}

Malaysian Chinese teacher training includes different categories. In terms of training personnel, both the in-service teachers and the school administrators are included. At the training level, it covers the training of teachers from Chinese kindergarten to primary school and middle school. In terms of training content, it includes Chinese teachers' teaching skills, Chinese basic knowledge and culture, using teaching materials, class management, teacher's emotion management and other aspects.

\section{3) School-based Training--an Important Way of Teacher's} Training

School-based training is based on the actual needs of teachers in each school, and the training method is customized. The education department of the New Era University is a vital institution of training Chinese teachers, especially the teachers in Malaysia Chinese Independent Secondary School. The teaching environment of Chinese language in Malaysia is complicated. The objects of learning Chinese include Chinese and non-Chinese students, whose language background and Chinese level are different. Thus, teachers have to give students personalized guidance according to their different levels. In terms of teachers, the composition of Chinese teachers is also more complex. The teacher level is uneven. Malaysian Chinese teachers can be divided into four categories: first, teachers take Chinese as a native language with a high degree of Chinese knowledge and they use Chinese as first language of teaching experience; second, teachers take Chinese as a native language with a high degree of Chinese knowledge and they use Chinese as second language of teaching experience; third, teachers take Chinese as a native language with a high degree of Chinese knowledge but they don't have teaching experience of Chinese language; fourth, teachers take Chinese as a native language with deficient Chinese knowledge and teaching skills. Malaysian Chinese teachers have a wide range of professional backgrounds, for the Ministry of Education does not require a Chinese language background in the Chinese language teaching staff. Therefore, the complexity of Malaysian students and teachers has made school-based training a more popular training method in Chinese teachers' training.

\section{B. The Problem of Teacher Training in Chinese Language in Malaysia}

\section{1) Low Degree of Specialization in Teachers' Training}

There are thousands of temporary teachers in Chinese primary schools in Malaysia who are not qualified as teachers. Although the ministry of education has taken some training measures, the number of people assigned to enroll in the annual training is very limited. Many temporary teachers who qualified for training lose the opportunity to improve their professional level because they are unable to get the training qualifications. The temporary teacher is an important source of Chinese language teachers, and the professional level of the temporary teacher directly affects the quality of Chinese language teaching. The professional level of Chinese teachers in Malaysia Chinese Independent Secondary School is also very weak. According to the basic statistics of the national Chinese language independent middle school in 2015, in Malaysia Chinese Independent Secondary School, 57.44 percent of teachers are not qualified as teachers. At present, due to institutional problems in Malaysia Chinese Independent Secondary School, it faces practical difficulties for lack of effective professional training mechanism and training personnel. Currently, the training of teachers in Malaysia Chinese Independent Secondary School mainly depends on New Era University and Chinese universities in Taiwan and mainland. However, the fact that Taiwan and mainland of China have little understanding of the actual needs of the teaching in this school, which to some extent has slowed the professionalization of the Chinese language teachers. There is a lack of careful planning in the in-service education of teachers in the school, which is mainly the short training time of teachers so that they are unable to further study, and the training is short of initiative and interactivity. In addition, the ministry of education also failed to put a good deal in the process of recruitment, so that many trainees who do not have the background of Chinese language learning sneak into the teaching staff, so the training quality is difficult to guarantee.

2) The Ministry of Education's Indifference of Teachers' Training

From the current training situation of Chinese teachers in Malaysia, it can be found that the training institutions of Chinese teachers in Malaysia are mainly focused on the UCSCAM, the Faculty of Education and the Education Department of the New Era University. The Ministry of Education of Malaysia and the schools in the system have inadequate training of Chinese language teachers, so the main subjects of the training only includes temporary teachers in Chinese language schools and pre-service Chinese language teachers. The Ministry of Education has neglected the training of Chinese language teachers, which is attributed to the single educational policy in Malaysia for many years. Therefore, it is difficult for Chinese language teachers to get the support of the government, and the teachers' training can not implement the management of institutionalization and specialization.

\section{ENLIGHTENMENT TO THE TRAINING OF INTERNATIONAL Chinese Language Teachers}

Malaysian Chinese language teacher is a model of localized Chinese language teachers in Southeast Asia. Under the general background of the Mandarin fever and One Belt and Road, the Southeast Asian countries urgently need a large number of high-quality talents who can speak Chinese. There are many problem in Malaysian education of Chinese teacher and it is still in the development stage, but in general, the teaching experience of Malaysian Chinese teachers is relatively abundant, which is worth learning from southeast Asian countries, and it also has some reference values for the Chinese training of professional talents both at home and abroad. 
A. Ministry of Education, Schools and Chinese Communities--the Educational Bases of Local Chinese Language Teachers

The cultivation of local Chinese language teachers needs to balance the power of the Ministry of Education, schools and the Chinese communities. The Ministry of Education should make the top-level design of education for Chinese teachers, including professional system, qualification certification system, promotion system, further education system, welfare treatment and other aspects. Schools can develop the corresponding training program for Chinese language teachers according to the policy and system of the Ministry of Education and carry out the school-based researches.

\section{B. Using the Advantage of Geography, Language and Culture to Cultivate International Chinese Language Teachers}

The continuous promotion of One Belt and Road puts forward more pressing needs for the training of international Chinese language teachers. ASEAN is an important country in maritime silk road, having natural location advantages with coastal cities of southeast China and three provinces of Southwest China (namely Guangxi, Yunnan, Tibet). Not only the geographical location is close, but also it has the advantage of minority languages, so that the degree of culture identify is high. It can be seen that universities in southeast and southwest of China have an obvious advantage in the cultivation of international Chinese talents for Southeast Asia. Universities in China also make full use of the regional advantages to adapt to the realistic demand of nationalized and localized Chinese language teachers. Similarly, countries along One Belt and Road in the process of local Chinese language teacher training should also consider location advantages, strengthen the communication and cooperation with neighboring countries, and jointly commit to the improvement of education quality of Chinese talents. In Southeast Asia, for example, Malay is the official language of Malaysia, Singapore and Brunei. And the tagalog of the Philippines and the Indonesian language are very close to Malay, so the people in these countries can communicate easily. These countries have a large number of Chinese and similar cultures, which need to cultivate a large number of local Chinese teachers. And the local Chinese teachers can meet the needs of Chinese teachers in other countries. Therefore, the training of Chinese teachers in different countries should take advantages of the similarities and geographical advantages, make up for the deficiency by mutually borrowing experience, and meet the demand of Chinese talents in international market.

\section{Setting up the Local Chinese Language Teacher Curriculum}

The local Chinese language teacher training should be in line with the local Chinese teaching and the actual demand to establish the local teacher curriculum. Chinese teachers can be better qualified for Chinese language teaching only if they have a deep understanding of Chinese history, culture, society, politics, language and art, etc.. Therefore, Chinese language teacher training in southeast Asia and other countries can be opened to some localized curriculum for the country or a circle of culture, such as Chinese language education, Chinese politics and culture, Chinese society and culture, Chinese literature and so on.

\section{Cultivating Compound Chinese Language Teachers}

With the diversified trend of Chinese language teaching, the teaching nature of Chinese language has become more complicated. The current Chinese teaching has several natures, not only has the nature of mother tongue, first language, second language and even third language, but also has the nature between first and second languages. Therefore, the target of Chinese teacher training should be redefined. The training should have the ability to manage comprehensive ability and compound thinking of different Chinese language teaching properties, to transform teaching method to teaching object freely and to conduct personalized teaching of compound Chinese teachers.

\section{E. Developing Training Materials to Local Chinese Language Teachers}

Training materials of local Chinese language teachers is the guarantee of the promotion of the professional level of Chinese teachers. Different countries have different languages, so the expression of Chinese is different. The teaching materials of Chinese language teachers should be developed effectively according to the different levels and objects of Chinese language teaching combined with the key points and difficulties of local Chinese teaching.

To sum up, Malaysian Chinese language teacher training has certain advantages, which also presents new trends. But the specialization degree and strength of support from Ministry of Education in Chinese language teachers have yet to be improved. The training experience of Malaysian Chinese teachers can be used to provide reference for Southeast Asian countries and international Chinese teachers.

\section{REFERENCES}

[1] Xie Tingting, Research of the Chinese Teacher Localization in the International Promotion of Chinese Language--with ZhiXing Chinese Teaching College in Indonesia as an Example. Master Degree Thesis of Chongqing Normal University, 2014.

[2] Wang Huanzhi, The features, problems and countermeasures of teacher education in Malaysian Chinese independent high school. Education Review , 2014 (12).

[3] Ke Wenjing, The difficulties of teacher development in Malaysian Chinese education: Based on Overseas Chinese Education News. Overseas Chinese Education, 2017(3).

[4] $\mathrm{Yu}$ Kehua \& $\mathrm{Xu}$ Lili, The current situation, problems and countermeasures of Malaysia Chinese education under the background of diversification. International Chinese Language Education, 2017(2).

[5] Wan Ruixin \& Wang Shuhui, A review of the conference of "Theory and Practice of Teaching Chinese Language" in Malaysia . Overseas Chinese Education, 2017 (2)

[6] Mo Shunzong, Cultivating native Chinese teachers in Southeast Asia: The role of Malaysia and the New Era College. In Proceedings of the 2014 World Chinese Education Forum. Kuala Lumpur: New Era College. pp.381-385. 2014.

[7] Wang Shuhui, In Malaysian Chinese independent high school teacher inservice training--Take the courses offered by the New Era College as an 
example. In Proceedings of the 2014 World Chinese Education Forum. Kuala Lumpur: New Era College.pp.397-406. 2014.

[8] Wan Ruixin, The direction of training of local mandarin teachers in Malaysia. Malaysian Journal of Humanities and Social sciences , 2016 (2).
[9] Zheng Guofu, Fundamental aspects of teacher education: based on the on-campus training in Yong Peng High School. Malaysian Journal of Humanities and Social sciences, 2016(1).

[10] Wang Shuhui, In service teacher training: the experience of Malaysian Chinese independent high school. Malaysian Journal of Humanities and Social sciences, 2015(2). 